\title{
LEVEL OF FINANCIAL LITERACY OF ACADEMIC YOUTH FROM RURAL AND URBAN AREAS
}

\author{
Josef Polák ${ }^{1}$ \\ Zuzana Kozubíková ${ }^{2}$ \\ Aleš Kozubík ${ }^{3}$ (D)
}

Received: June 29, 2021 / Revised: October 15, 2021 / Accepted: October 29, 2021

(C) Association of Economists and Managers of the Balkans, 2021

\begin{abstract}
Financial literacy is becoming one of the key competencies in the 21st century. In its absence, it is virtually impossible to navigate the market for financial products and services and thus ensure financial stability throughout a whole life. This fact is all the more important given the threats arising from the effects of the pandemic crisis. Thanks to exhausted public budgets and the cooling of the economy, it can be expected that, despite strong regulation, there will be more aggressive sell practices on the market, to which financially literate people are more resilient. The aim of the study is to determine the level of financial literacy of academic youth from rural areas and to compare the results obtained with the level of financial literacy of young people from cities. The source of data used for analysis and inference was primary information obtained from own questionnaire research. To assess the level of financial literacy, the authors use an innovative metric, the personal finance index. In addition to overall success, this approach also makes it possible to analyze knowledge from the eight functional areas of financial literacy. By comparing the results in single areas, the authors reveal that risk management is Achyla's heel of financial literacy. The authors focus on the differences in financial literacy according to the place of residence. The study explores inequalities in the single functional areas of financial literacy between the respondents living in the urban and rural areas.
\end{abstract}

Keywords: Decision making, Financial education, Financial knowledge, Financial logic, Financial management, Questionnaire survey.

JEL Classification D71 · G41

josef.polak@ambis.cz

AMBIS University, Department of Economics and Management, Lindnerova 1, 18000 Prague 8, Czech Republic University of Žilina, Faculty of Management Science and Informatics, Univerzitná 8215/1, 01026 Žilina, Slovakia University of Žilina, Faculty of Management Science and Informatics, Univerzitná 8215/1, 01026 Žilina, Slovakia 


\section{INTRODUCTION}

The exposition to rapid and dynamic changes is one of the characteristic features of life in the modern society of the 21st century. Nearly everyone is aware of the impact of modern technology, but people also need to understand that almost daily their lives are becoming more closely linked to complex financial markets. The post-covid period and the associated aid programs only highlighted this fact. The choice of appropriate assistance, deferral of loan repayments, must always be carefully considered with regard to its possible future impact.

Financial literacy belongs to the core life skills for people living in modern society. One can characterize it as knowledge of personal financial management. It provides a double advantage in protection against financial losses and frauds as well as in planning a financially secure future. Financial literacy gives consumers the necessary knowledge and skills to assess the suitability of the various financial products and investments available in the financial market.

In our study, we focus on academic youth, and our objective is to examine the influence of the socio-demographic factor, which is the nature of the place of residence, on the level of financial literacy. The type of residence is closely linked to the use and availability of financial services and subsequent practical experience. Based on our previous research (Polák, Kozubíková, \& Kozubík, 2018), we formulated a research hypothesis:

Hypothesis One: The financial literacy of the inhabitants of rural settlements and urban agglomerations is different.

The use of the Personal finance index enabled a structured approach to individual functional areas of financial literacy. Therefore, it was possible to analyze potential differences and verify or refute the validity of hypothesis number two:

Hypothesis Two: Respondents' knowledge is uniformly distributed in all functional areas.

Since our expectations were, based on our experience of pedagogical work, entirely the opposite, we also formulated the third hypothesis:

Hypothesis Three: For all types of residence, the decline in competencies are reflected in the same functional areas.

\section{LITERATURE REVIEW}

One can find in the literature several more or less complex definitions of financial literacy. For instance, Mandell defined financial literacy as The ability to evaluate the new and complex financial instruments and make informed judgments about both: choices of instruments and extent of use that would be in their own best long-run interests (Mandell, 2007). Remund says that financial literacy is a measure of the degree to which one understands key financial concepts and possesses the ability and confidence to manage personal finances through appropriate short-term decision-making and sound, long-range financial planning, while mindful of life events and changing economic conditions (Remund, 2010). The study by Giesler \& Veresiu (2014) defines financial literacy as The ability to understand how money works in the world: how someone manages to earn or make it, how that person manages it, how he/she invests it (turn it into more) and how that person donates it to help others. To measure financial literacy among adults, the OECD/INFE 
developed the definition: Financial literacy is a combination of awareness, knowledge, skill, attitude, and behavior necessary to make sound financial decisions and ultimately achieve individual financial well-being (Atkinson \& Messy, 2012).

The PISA Financial Literacy Assessment Framework (OECD, 2019) refines the definition used for adults to make it relevant for 15-year-old students: Financial literacy is knowledge and understanding of financial concepts and risks, and the skills, motivation, and confidence to apply such knowledge and understanding in order to make effective decisions across a range of financial contexts, to improve the financial well-being of individuals and society, and to enable participation in economic life.

The importance of financial literacy is emphasized by several authors. A strong positive relationship between financial literacy and the wealth of households is reported in van Rooij, Lusardi \& Alessie (2012). Our findings provide evidence of a strong positive association between financial literacy and net worth, even after controlling for many determinants of wealth.

A number of studies and research examine financial literacy and financial inclusion in terms of service availability, information, potential benefits, and financial education. Research by Di Giannatale \& Roa (2019) examined different barriers to formal saving, considering various interventions and their possible effects at microeconomic and macroeconomic levels. This study used and confirmed the results by Dupas et al. (2019) stating that the possible availability of acquiring free or very affordable savings products, administrative simplicity, and the ability to have a minimum of balances minimize barriers to financial inclusion of poor households. Di Giannatale \& Roa (2019) also mention the importance of understanding all the barriers that are linked to the use of financial products. Barriers include social ties that lead to informal transfers, low levels of financial education, lack of trust in formal financial institutions, and behavioral biases. In this light of information, their research states that financial education programs should provide information about savings products as well as the benefits of saving.

Research by Ansong et al. (2019) talks about the positive impact of the availability of possibilities of saving for studies and appeal for financial inclusion. Their results state that treatment effects on school attendance and academic performance were examined using difference-in-difference estimation with bootstrapped standard errors when their results show that treatment effects were significant for attendance but not performance. Their wide study demonstrated the potential of asset-accumulation programs can contribute to improved behavioral outcomes and offers insights for the integration of financial capability programs in youth development policies on pupils from public schools in Ghana.

The paper of Potocki (2019) examines low-income households' financial capability by looking at their financial literacy, financial behavior as well as financial inclusion among low-income households from rural and peripheral parts of Poland. Research has found that financial literacy among these households is very low, but also some positive literacy factors underlining the importance of numeracy, risk literacy, and debt literacy, in particular, can be found. This situation is associated with literacy in general, however, the author emphasizes the need for financial literacy.

The low level of financial literacy may result in the incapability to use a full range of financial opportunities, prevent households from having the capability to make responsible financial choices, like being able to understand product mechanisms and product descriptions, and put at risk some other core functionalities, such as psychological health (Marmot, 2005; Pollack \& Lynch, 2009; Potocki, 2019). 
Potocki (2019) also mentioned some identified „financial management skills” consisting of abilities allowing to manage a financial budget and keep track of expenditure, which connects more with survival skills and the local culture than with financial education attendance. Thus, households behave responsibly and carefully, they first save before taking any action in the form of decisions, for which they need to be financially informed, which motivates them to financial education. However, they think in the short term, which leads to proper day-to-day money management, but it has implications for the short term thinking in planning and/or low propensity to save. This is evidenced by the study of Kempson, Perotti \& Scott (2013).

According to Potocki (2019), it is necessary to take into account the factors of financial inclusion based on research in low-income families from rural areas. Adapting to low income does reduce financial stress and frustration, but structural constraints do not increase household income, leading to further effects. People can have low ambitions, they do not use their abilities, they do not focus on long-term savings, which can have a destructive impact on the financial possibilities of these households. This is especially true for post-communist countries, where risk avoidance, passivity, and survival attitude lead to short-term thinking.

However, the issue of financial literacy and inclusion is not a topic of developing and post-communist countries. From the point of view of the currently solved migration, this issue becomes more important, because it can lead to import ingrained behavioral patterns and complications in the process of integration (Palát, 2014). The need for financial inclusion even in developed market economies is underlined by research (Nam \& Loibl, 2021), which states that almost a third of older adults over the age of 55 in the United States have neither retirement savings nor accumulated retirement benefits. Their research focused on low-income adults. Their findings are also reflected in the behavior of middle-income households. They emphasize the need for broad education in financial literacy across all age groups. The authors consider the current formal education at secondary and post-secondary institutions to be insufficient and point to the need for further education in the workplace.

In Europe Huang, Kale, Paramati \& Taghizadeh-Hesary (2021) examined the role of financial inclusion in economic output in a sample of $27 \mathrm{EU}$ member countries. To confirm the reliability of the results they classified the full sample into old-EU, new-EU, high-income EU, and low-income EU economies. The authors measured economic development through indicators of GDP and per capita GDP. Their study also controlled for various factors (eg. energy use, capital, labor, and trade openness) and used yearly data from 1995 - 2015 as well as panel econometric techniques. Their study confirmed that financial inclusion has played a significant and positive role in promoting economic performance across EU nations, with the impact of financial inclusion on economic growth being much stronger in the new EU and low-income EU countries. These results point to significant space to expand and develop the markets.

\section{METHODOLOGY}

As a measuring tool of students' financial literacy, we used an innovative measure introduced in Lusardi, Yakoboski \& Oggero (2017) as a personal finance index (shortly P-Fin index). This tool measures the knowledge and level of comprehension necessary to manage personal finances effectively and make a financial decision correctly. The authors mentioned above have designed the P-Fin index to cover the eight functional areas of financial literacy that an individual commonly encounters in managing personal finances. These areas are:

- earnings, determinants of wages and income,

- $\quad$ consuming, budgeting and spending, 
- $\quad$ saving, comprehension the accumulation factors,

- $\quad$ investing, understanding the types and risks of investments,

- $\quad$ borrowing and debt management,

- $\quad$ risk management, comprehension of the uncertain outcomes,

- insurance and the understanding of coverages,

- $\quad$ accessing and working with information sources.

The data necessary for the analysis we have collected by the method of questionnaire survey. The knowledge testing part of the questionnaire consisted of 30 multiple-choice questions. Each of the functional areas of financial literacy was covered by three or four questions. Respondents entered the answers as a choice of four options, one of which was correct, and one option was the „I don't know" option. Besides the knowledge questions, the questionnaire contained questions concerned with socio-demographic data such as age, gender, education, the residence.

We conducted our questionnaire survey at two universities. One of them is located in Czechia, and the other in Slovakia. From the 425 answer sheets received, 238 were from Slovakia, and the remaining 187 were from the Czech Republic. We focused the research on students of the first (bachelor's) degree in economics and management. It represents young people aged between 18 and 25. All of them had completed secondary education at different types of schools. Almost half of the students, 207 to be precise, were graduates of grammar schools, another 80 were graduates of industrial schools and 86 were graduates of vocational secondary schools. Only 52 respondents, representing approximately $12 \%$, were graduates of trade academies. It is only in this small, latter group that it is possible to assume some foundation of previous formal economic education.

A crucial element was determining which residences we would consider rural and urban. The usual criterion for assessing the type of residence is the number of inhabitants. The distinction into three categories proved to be expedient, namely rural settlements, small and medium-sized towns (we will further refer to as urban) and large metropolises. Following customs, we have chosen 5,000 inhabitants as the upper limit for the rural settlement. Given the total population in both countries, we set the limit for metropolitan centers at 100,000, which is met by regional capitals.

The notion of stochastic dominance was used to compare the empirical distributions. It provides a partial ordering between the random variables. For our purposes, we applied the first-order stochastic dominance rule. Let $X$ and $Y$ be two random variables with the cumulative distribution functions $F_{X}(x)$, and $F_{Y}(x)$ respectively. We say that $X$ dominates $Y$ (in the sense of the first-order stochastic dominance) if $F_{X}(x) \leq F_{Y}(x)$ for all $x$, where a strict inequality holds for at least one $x$. Expressed by the language of probabilities it means that $P[X \geq x] \geq P[Y \geq x]$ for all $x$, and the strict inequality $P[X \geq x]>P[Y \geq x]$ holds for at least one $x$. So the random variable $X$ tends to reach higher values than random variable $Y$.

The tests of the statistical hypotheses about the equality of mean percentages, we conducted using the Welch t-test that implemented in the R environment. Also, all other calculations and graphical outputs have run in this environment.

\section{RESULTS}

Our sample contained a total of 425 completed questionnaires. Since we distributed 540 questionnaires as a whole, the corresponding return rate is $78.7 \%$. We summarized the numbers of respondents according to the size of settlements in Table 1. 
Table 1. Counts and percentages of respondents according to the type of their residence

\begin{tabular}{|c|c|c|c|}
\cline { 2 - 4 } \multicolumn{1}{c|}{} & \multicolumn{3}{c|}{ Type of residence } \\
\cline { 2 - 4 } \multicolumn{1}{c|}{} & Rural & Urban & Metropolises \\
\hline Count & 249 & 112 & 64 \\
\hline Percentage & $58.59 \%$ & $26.35 \%$ & $15.06 \%$ \\
\hline
\end{tabular}

Source: Own elaboration

Figure 1 illustrates the percentages of correct and incorrect answers as well as „I do not know” answers in each functional area of financial literacy.

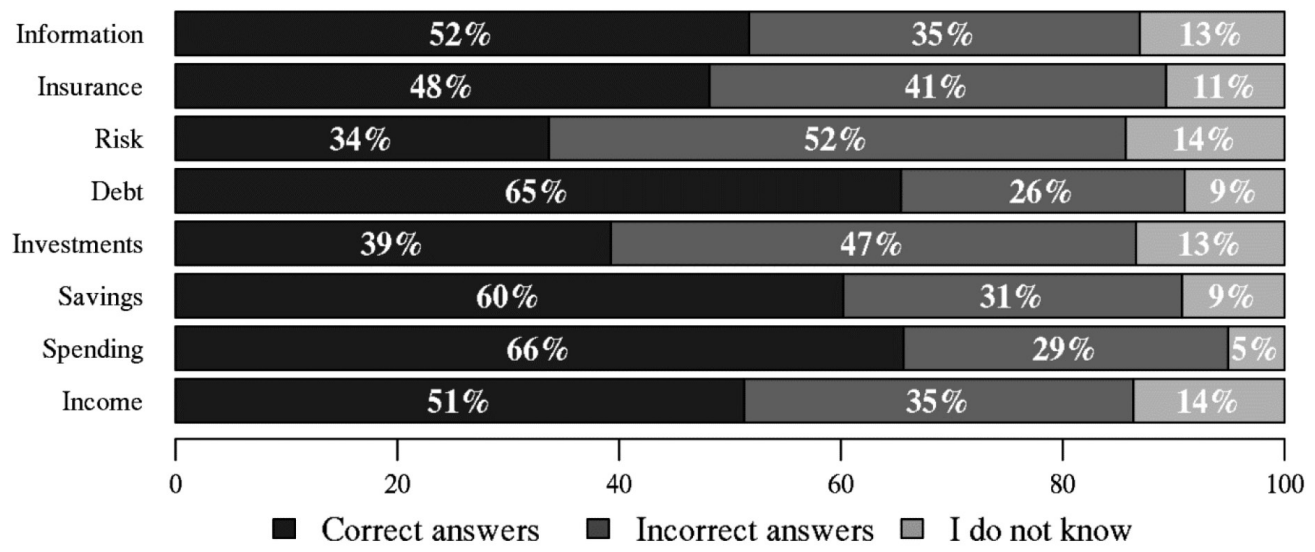

Figure 1. Percentages of correct and incorrect answers and „don't know” answers in single functional fields.

Source: Own elaboration

In Figures 2-4, we then graphically present these shares broken down by type of residence. The figures document the higher proportion of correct answers among respondents from metropolitan areas. They also show a decrease in the share of „I do not know” responses. The highest proportions of ,I do not know” answers were among the inhabitants of small and medium-sized towns, and if this proportion decreased in some functional areas, it was reflected in a higher rate of incorrect answers.

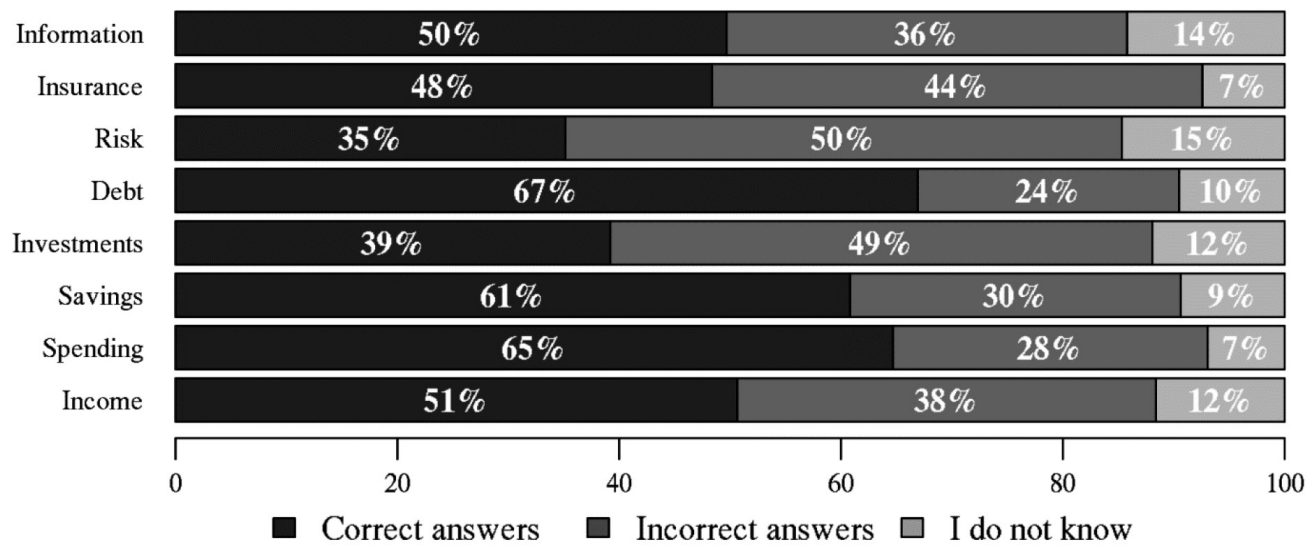

Figure 2. Percentages of correct and incorrect answers and „I don’t know” responses in single functional fields by rural areas inhabitants

Source: Own elaboration 


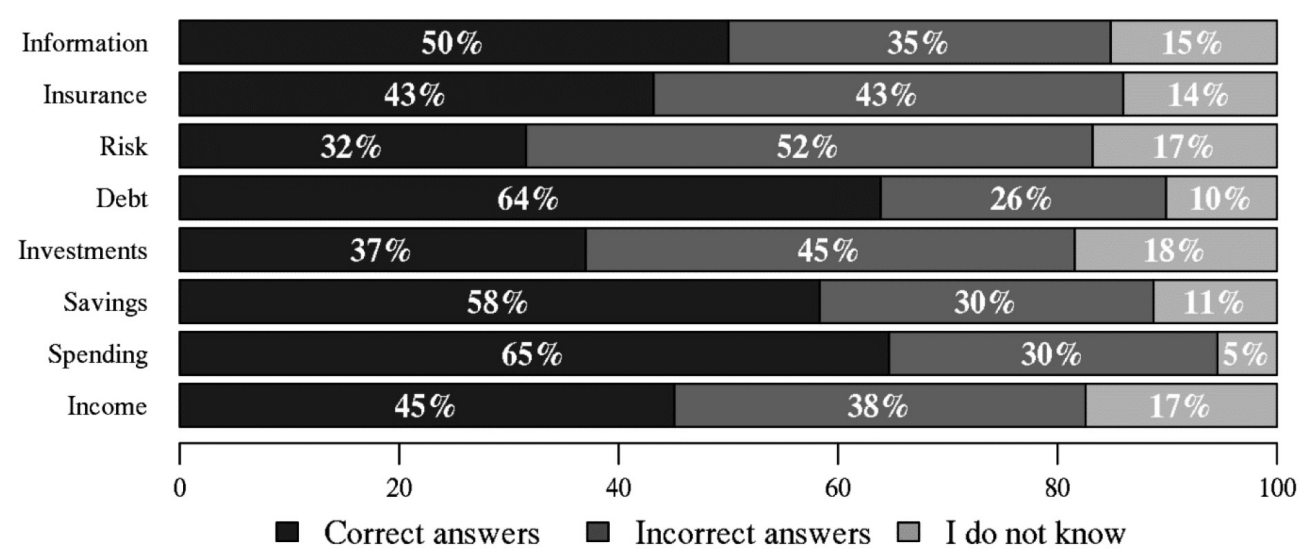

Figure 3. Percentages of correct and incorrect answers and „I don't know” responses in single functional fields by urban areas inhabitants.

Source: Own elaboration

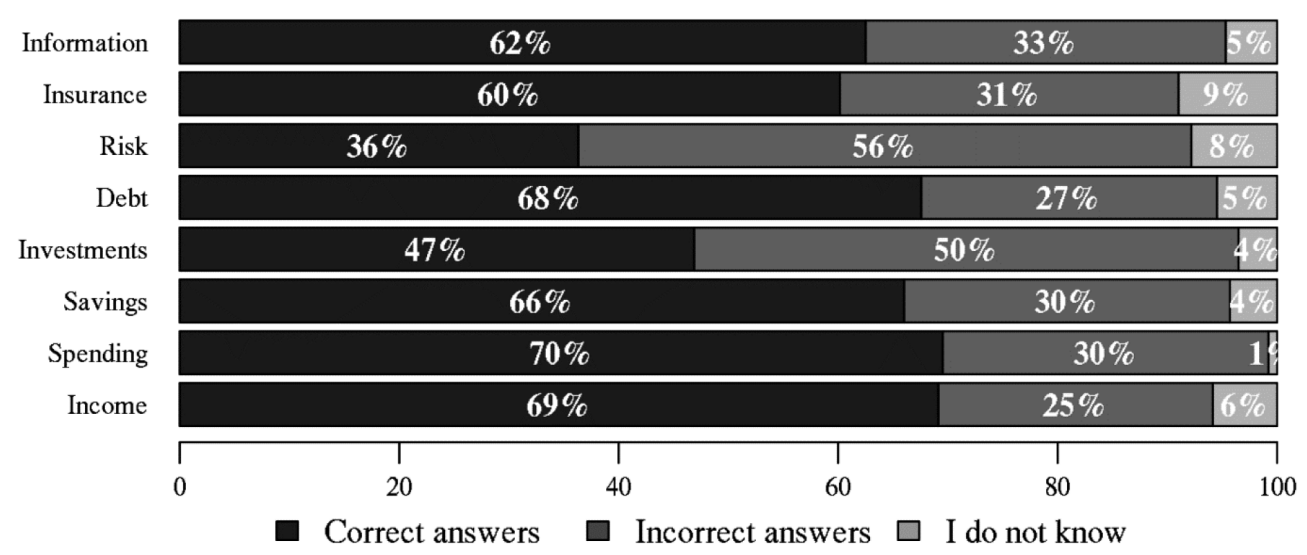

Figure 4. Percentages of correct and incorrect answers and „I don’t know” responses in single functional fields by metropolises inhabitants.

Source: Own elaboration

We confirmed the different average success rates among the respondents from the different types of residence using the Welch t-test for equality of means. We have summarized the results in Table $2-4$. We see that we can reject the hypothesis of equality of mean values case by case with very high confidence, $p$-values range between 0.027 and $3.6 \cdot 10^{-6}$.

Table 2. Results of the Welch t-test of equality of the mean percentages for the residents of rural areas and small and medium-sized cities

\begin{tabular}{|l|c|c|c|}
\hline Type of residence & Mean percentage & t-statistics & p-value \\
\hline Rural & $52.09 \%$ & \multirow{2}{*}{0.9286} & 0.02735 \\
\hline Urban & $49.16 \%$ & & \\
\hline
\end{tabular}

Source: Own elaboration 
Table 3. Results of the Welch t-test of equality of the mean percentages for the residents of rural areas and metropolises

\begin{tabular}{|l|c|c|c|}
\hline Type of residence & Mean percentage & t-statistics & p-value \\
\cline { 1 - 2 } Rural & $49.16 \%$ & -4.7592 & 0.00082 \\
\hline Metropolises & $59.58 \%$ & & 0.002 \\
\hline
\end{tabular}

Source: Own elaboration

Table 4. Results of the Welch t-test of equality of the mean percentages for the residents of small and medium-sized cities and metropolises

\begin{tabular}{|l|l|l|l|}
\hline Type of residence & \multicolumn{1}{|c|}{ Mean percentage } & t-statistics & \multicolumn{1}{c|}{ p-value } \\
\hline Urban & $52.09 \%$ & \multirow{2}{*}{-3.2284} & $3.6 \cdot 10^{-6}$ \\
\hline Metropolises & $59.58 \%$ & & \\
\hline
\end{tabular}

Source: Own elaboration

Figure 5 illustrates a comparison of the empirical densities and distribution functions of percentage successes for individual housing types. How one can see, the distribution function graph is shifted to the right in the case of metropolises compared to both other residence types. It is thus clear that the performance of the metropolitan inhabitants stochastically dominates over other localities. Similarly, the graph of the distribution function for the answer percentages of the inhabitants of rural areas is completely shifted to the right compared to the inhabitants of small and medium-sized towns. Thus, even these respondents stochastically dominate the inhabitants of urban areas. So we get a clear ranking of the level of financial literacy according to the type of residence.
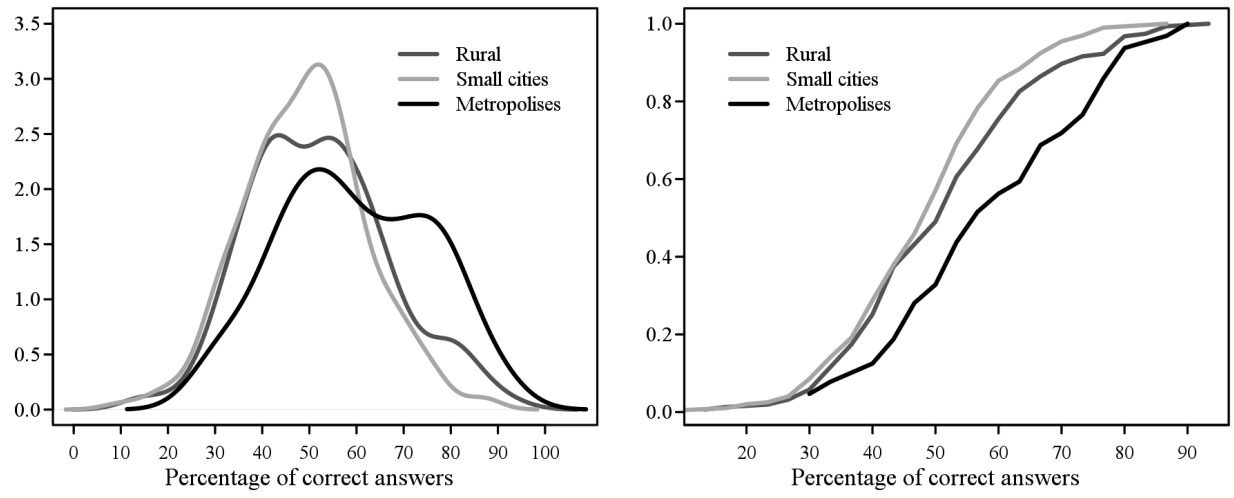

Figure 5. Graphs of the empirical densities (on left) and empirical distribution functions (on right) of the percentages according to the type of residence

Source: Own elaboration

It is also worth noting the comparison of empirical densities in Figure 5 on the left. While the current percentages of respondents in urban residences have a mode at 50\% approximately, bimodal probability distributions appear in rural areas and metropolises. This shift is particularly notable in the case of metropolitan residents. Here, the secondary mode becomes visible at a high level of percentages of almost $80 \%$.

The disparities between the average scores in the individual functional areas of the P-Fin index are easily visible in the radar graphs in Figures 6 and 7. In all four cases, we see a significant drop in average scores in risk management and investment decisions, which is also associated with risk perception. 


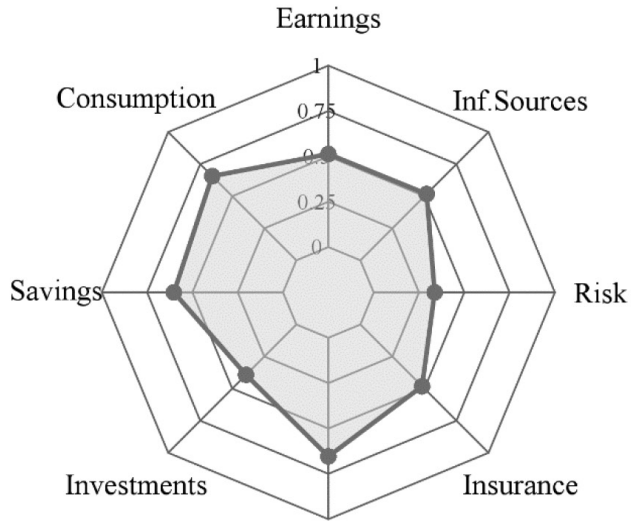

Debt

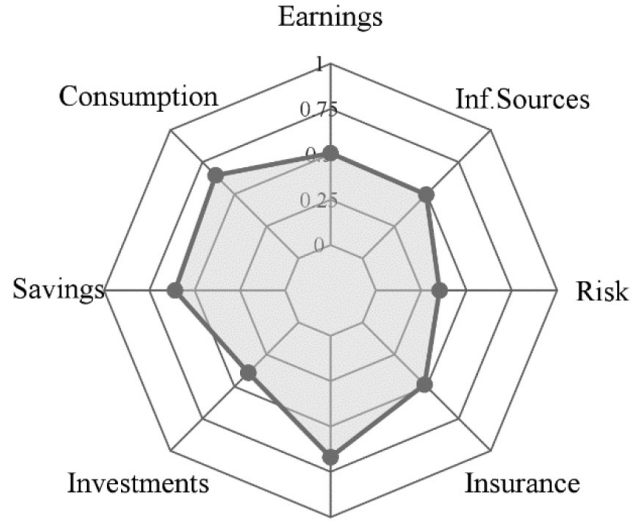

Debt

Figure 6. Radar graph of average scores by single areas of the P-Fin index in the whole sample (left) and metropolises inhabitants (right).

Source: Own elaboration

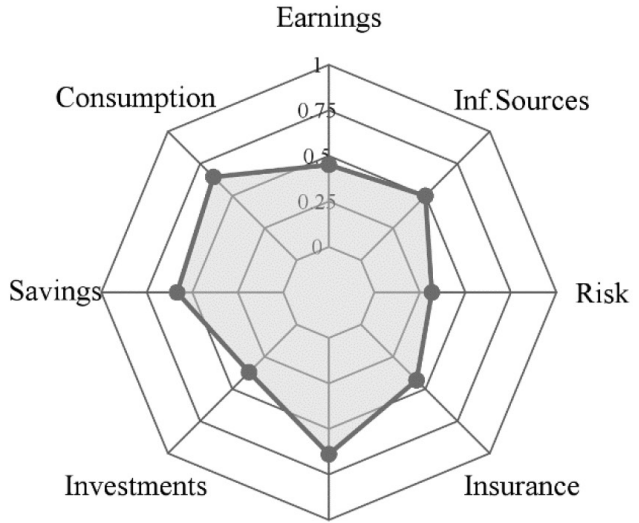

Debt

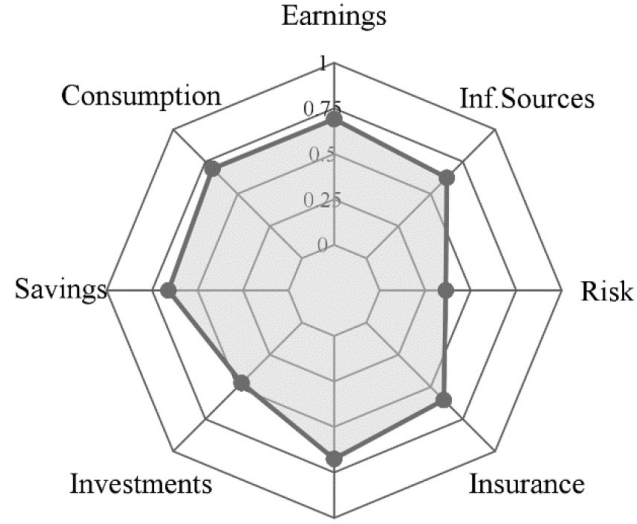

Debt

Figure 7. Radar graph of average scores by single areas of the P-Fin index according to the residence type: urban areas (left) and metropolises (right).

Source: Own elaboration

Further, we can observe significantly better results of the large metropolises inhabitants in the field of earnings, determinants of wages and income. As well as in accessing and working with information sources or consuming, budgeting and spending they achieved higher average score. However, the asymmetry of radar graphs generally indicates a non-uniformity of skills in individual functional fields.

\section{DISCUSSION}

As we can see from the graphs in Figures 1-4, in most functional areas, the respondents achieved more than half the success of the answers. The only exceptions are issues related to risk management, investment, and positioning, which means risk issues in general. However, some positive shift in the population of large metropolises is evident. There were fewer „I don't know” answers, and this decline was reflected in an increase in the correct answers. One can explain this result by 
the influence of financial inclusion, which is defined as the availability and equality of opportunities to access financial services. Inhabitants of the large metropolises encounter more likely the issue, thanks to the easier availability of financial services.

Conversely, in smaller towns or rural settlements, the availability of financial services is limited, often offered by a single provider, so there is no need for decision-making and practical experience. It confirms the results of our previous research (Polák, Kozubíková \& Kozubík 2018) on the positive impact of practice on financial literacy. The results of the statistical tests presented in Tables 2-4 then confirm the validity of our research hypothesis one.

The surprising result is that in small and medium-sized towns, there was a higher proportion of „I don't know” answers and a lower proportion of correct answers than in rural settlements. It would be under the influence of financial inclusion that we would expect the opposite effect. We can explain this disproportion in a different way of life. A conservative family lifestyle still prevails in rural areas. Young people are thus more involved in all areas of life, including financial decision-making. They have closer contact with parents, take over their experience, and are able to apply them. When comparing the success rate of responses in individual functional areas of financial literacy using radar graphs, we revealed irregularities in the distribution of abilities according to the components of the P-Fin index. This ruled out the validity of hypothesis two. On the contrary, a similar distortion of the symmetry of the graphs in all cases confirmed the validity of research hypothesis three.

If we combine the results of our research with the findings of Di Giannatale \& Roa (2019), Ansong et al. (2019) and Potocki (2019) it is clear that the issue of financial literacy and inclusion must start with young people and continue with the development of society and changes in the financial market, otherwise, we face the generations who are on the verge of productive age with low income to relatively fundamental problems in ensuring a dignified life already on the threshold of their retirement age.

From the results of our research and research Huang, Kale, Paramati \& Taghizadeh-Hesary (2021) it follows that within the EU there is space for expansion and development of the markets through financial inclusion, but the development of financial literacy and financial inclusion is essential for development. individual regions. This development can be expected to have positive macroeconomic impacts, but at the same time, it will help them to develop rural areas and address the issue of ensuring a decent living for low-income households.

The stabilized development of the lower and middle classes will subsequently be reflected in the corporate sphere thanks to the sustainable purchasing power of a wider range of the population, which will be able to take care of themselves without a higher burden on the social system. In the case of deepening social problems in the lower and middle class associated with the subject area of our research, we can expect a deepening of the negatives mentioned in the research of Nam \& Loibl (2021) and Potocki (2019).

\section{FUTURE RESEARCH DIRECTIONS}

The research is beneficial because of primary data and because complements and builds findings of the above investigation carried out in the Czech Republic and Slovakia. These countries are among the newer EU members, where households do not have a high income but have a stable economy. Research has the perspective to be developed in various areas, e.g. in the problems of 
regional development in connection with the financial literacy level and financial inclusion. This matter is also related to the issue of expansion and performance of companies and enterprises. Companies need a skilled workforce and also an abundant and stable space for their sales.

\section{CONCLUSION}

Overall, we confirmed that in the academic youth segment, financial skills are unequally distributed among students from large agglomerations and rural settlements. One of the possible causes of this situation is closer contact with financial services. At the same time, we saw that in the functional areas associated with risk assessment, there is a significant decrease in skill in all groups. In education, it is, therefore, necessary to pay more attention to the development of probabilistic thinking as a tool for risk quantification and its connection with practical tasks.

\section{ACKNOWLEDGMENT}

The paper was conducted within the project KEGA No 007ŽU-4/2021 Innovative courses to improve financial and economic literacy of the technical fields' students and within science and research activities at AMBIS University, a.s.

\section{REFERENCES}

Ansong, D., Chowa, G., Masa, R., Despard, M., Sherraden, M., Wu, S., \& Osei-Akoto, I. (2019). Effects of Youth Savings Accounts on School Attendance and Academic Performance: Evidence from a Youth Savings Experiment. Journal of Family and Economic Issues, 40(2), 269-281. https://doi.org/10.1007/s10834-018-9604-5

Atkinson, A., \& Messy, F.-A. (2012). Measuring Financial Literacy: Results of the OECD / International Network on Financial Education (INFE) Pilot Study. OECD Working Papers on Finance, Insurance and Private Pensions, Vol. 15. https://doi.org/10.1787/5k9csfs90fr4-en

Di Giannatale, S., \& Roa, M. J. (2019). BARRIERS TO FORMAL SAVING: MICRO- AND MACROECONOMIC EFFECTS. Journal of Economic Surveys, 33(2), 541-566. https:// doi.org/10.1111/joes.12275

Dupas, P., Keats, A., \& Robinson, J. (2019). The Effect of Savings Accounts on Interpersonal Financial Relationships: Evidence from a Field Experiment in Rural Kenya. The Economic Journal, 129(617), 273-310. https://doi.org/10.1111/ecoj.12553

Giesler, M., \& Veresiu, E. (2014). Creating the Responsible Consumer: Moralistic Governance Regimes and Consumer Subjectivity. Journal of Consumer Research, 41 (3), pp.840 - 857. doi:10.1086/677842.

Huang, R., Kale, S., Paramati, S. R., \& Taghizadeh-Hesary, F. (2021). The nexus between financial inclusion and economic development: Comparison of old and new EU member countries. Economic Analysis and Policy, 69, 1-15. https://doi.org/10.1016/j.eap.2020.10.007

Kempson, E., Perotti, V., \& Scott, K. (2013). Measuring Financial Capability: A New Instrument and Results from Low- and Middle-Income Countries. New York. Retrieved from https:// openknowledge.worldbank.org/bitstream/handle/10986/16296/798060WP020Mea0Box0379791B00PUBLIC0.pdf? sequence=1\&isAllowed $=\mathrm{y}$

Lusardi, A., Yakoboski, P. J., \& Oggero, N. (2017). The TIAA Institute-GFLEC Personal Finance Index: A New Measure of Financial Literacy. New York: TIAA Institute.

Mandell, L. (2007). Financial literacy of high school students. In J.J. Xiao (Ed.), Handbook of Consumer Finance Research, New York, NY: Springer (pp. 163 - 183). 
Marmot, M. (2005). Social determinants of health inequalities. The Lancet, 365(9464), 10991104. https://doi.org/10.1016/S0140-6736(05)71146-6

Nam, Y., \& Loibl, C. (2021). Financial Capability and Financial Planning at the Verge of Retirement Age. Journal of Family and Economic Issues, 42(1), 133-150. https://doi.org/10.1007/ s10834-020-09699-4

OECD. (2019). PISA 2018 Assessment and Analytical Framework. PISA, OECD Publishing, Paris. https://doi.org/10.1787/b25efab8-en

Palát, M. (2014). The causes of migration initiation and reflections on related theories. In 17th International Colloquium on Regional sciences. Conference Proceedings. (pp. 708-714). Brno: Masaryk University Press. https://doi.org/10.5817/CZ.MUNI.P210-6840-2014-91

Polák, J.,Kozubíková,Z. \& Kozubík,A. (2018). Financial Literacy of University Students and Effects of Practical Experience. In SOCIOINT 2018, 5th International Conference on Education, Social Sciences and Humanities -Abstracts and Proceedings, Dubai, UAE 02-04 July 2018 (pp. 17-26). Istanbul, Ocerint International Organization Center of Academic Research.

Pollack, C. E., \& Lynch, J. (2009). Health Status of People Undergoing Foreclosure in the Philadelphia Region. American Journal of Public Health, 99(10), 1833-1839. https://doi.org/10.2105/ AJPH.2009.161380

Potocki, T. (2019). Financial capability among low-income households in rural parts of Poland. Argumenta Oeconomica, 2(43), 85-114. https://doi.org/10.15611/aoe.2019.2.04

Remund, D. L. (2010). Financial literacy explicated: The case for a clearer definition in an increasingly complex economy. Journal of consumer affairs, 44 (2), 276 - 295. doi: 10.1111/j.17456606.2010.01169.x

van Rooij, M. C. J., Lusardi, A., \& Alessie, R. J. M. (2012). Financial Literacy, Retirement Planning and Household Wealth. The Economic Journal, 122, pp. 449-478. doi10.1111/j.14680297.2012.02501.x 